\title{
Precipitation History of the Colorado Plateau Region, 1900-2000
}

he Colorado Plateau covers $210,000 \mathrm{~km}^{2}$
$\left(130,000 \mathrm{mi}^{2}\right)$ of Utah, Colorado, New
Mexico, and Arizona. Management of this
region's resources requires an understand-
ing of how its climate has varied in the
past and may change in the near future.
Recent studies by U.S. Geological Survey
(USGS) and other scientists suggest that the
region may become drier for the next 2 to 3
decades, in a pattern similar to the drought
of 1942-1977. The region's population has
increased fourfold since the mid-1950s, cre-
ating the possibility of severe consequences
if such a drought were repeated.

The Colorado Plateau, one of the most visually captivating parts of the United States, covers $210,000 \mathrm{~km}^{2}\left(130,000 \mathrm{mi}^{2}\right)$ of Utah, Colorado, New Mexico, and Arizona (fig. 1). Geologically, the plateau contains extensive areas of colorful, nearly horizontal, and essentially bare sedimentary rocks that are sculpted into plateaus, mesas, and deeply incised canyons, of which Grand Canyon is the classic example. The average elevation of the plateau is $1,500 \mathrm{~m}(5,000 \mathrm{ft})$, with peaks that rise to more than $3,700 \mathrm{~m}(12,000 \mathrm{ft})$. The region is arid to semiarid with sparse vegetation in the lowlands, forests in the mountains, and lush vegetation along the watercourses. The spectacular scenery, diverse ecosystems, and numerous important archeological sites are protected in 30 national parks and monuments.

Ranchers, environmental organizations, and agencies responsible for resource management in the parks, monuments, and other Federal and state lands of the region have a need to understand its long-term climate and how its climate may change in the near future. Regional precipitation varied substantially in the 20th century and is expected to decrease over the next 20 to 30 years. Scientists from diverse disciplines recently participated in a workshop to consider how landscapes and ecosystems in the Southwest might respond to a drier climate (Schmidt and Webb, 2001). A change to drier climate - particularly reduced winter rainfallwould have a variety of interrelated effects on plateau ecosystems. These may include

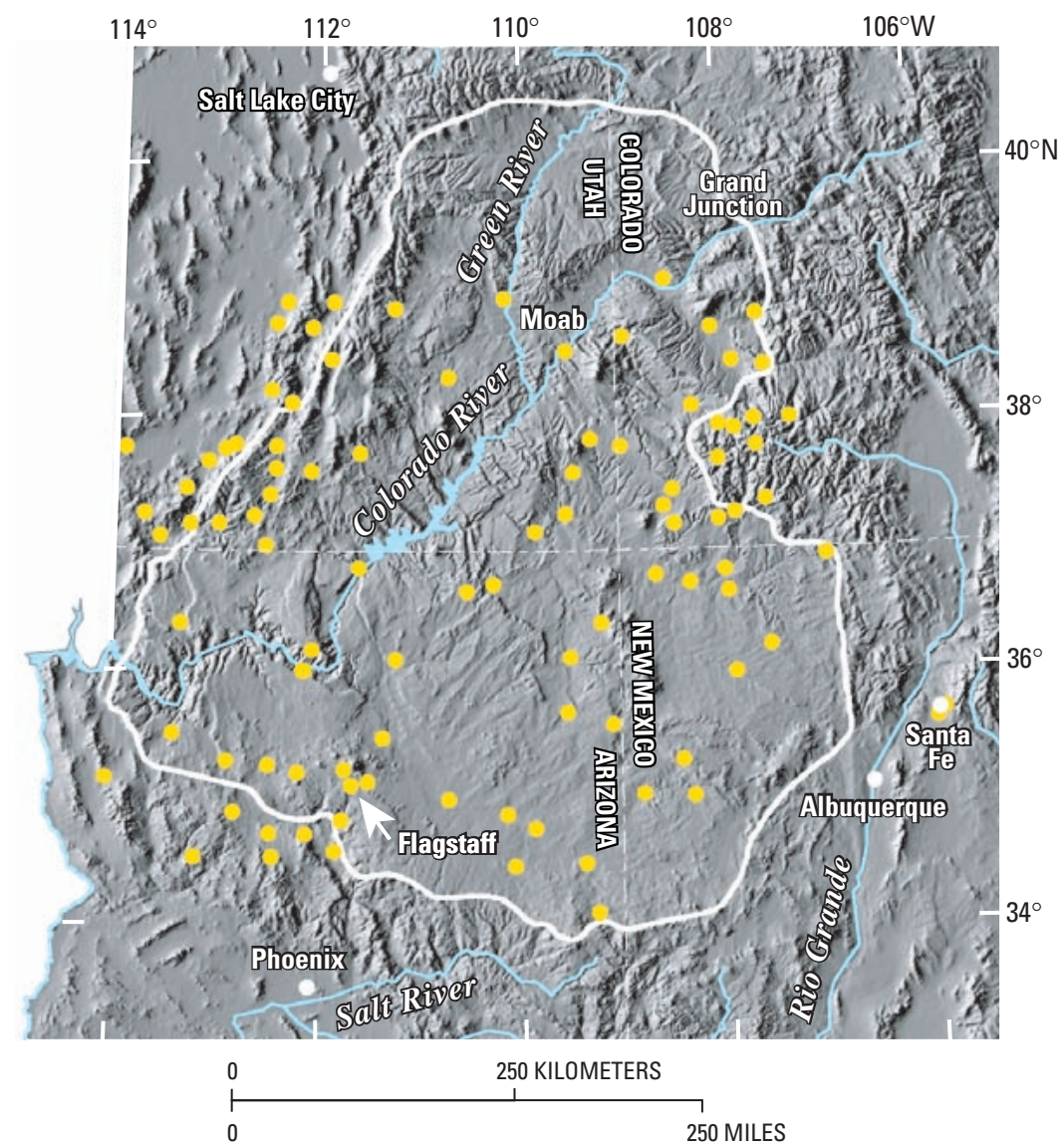

Figure 1. Regional setting of the Colorado Plateau (white outline), showing the 97 long-term weather stations (yellow dots) used to document the region's precipitation history.

reduced groundwater recharge, lower baseflow in perennial streams, increased frequency of dust storms and strong winds, weakening of biological soil crusts, reduction of plant cover and possible changes in species composition, remobilization of sand from previously stable dunes, and increased frequency of forest and range fires. This fact sheet discusses the 20th century precipitation patterns of the plateau, shows their relation to global climatic indices, and points out how precipitation may change in upcoming decades.

\section{Long-Term Variability of Annual Precipitation}

Average annual precipitation on the Colorado Plateau, based on analysis of daily records from 97 long-term weather stations (fig. 1), ranges from 136 to $668 \mathrm{~mm} / \mathrm{yr}$ (5.4 to $26.3 \mathrm{in} / \mathrm{yr}$ ), with a median precipitation of $300 \mathrm{~mm} / \mathrm{yr}$ (11.8 in/yr). Annually, precipitation varied substantially during the 20th century (fig. 2). Three multidecadal precipitation regimes are apparent in the precipitation history: 1905-1941, 1942-1977, and 1978-1998. Although the choice of limiting dates for these regimes is somewhat subjective, the middle period was clearly dry and was sandwiched between two wetter episodes. The early part of the dry regime (1942-1956) was recognized as a drought in the 1960s (Gatewood and others, 1964), perhaps the severest drought in the past 400 years in New Mexico (Swetnam and Betancourt, 1998). This drought affected much of the Southwest and lasted until 1977, although precipitation increased somewhat after 1956. The first 5 years of the 20th century (1900-1904) was the culmination of an 


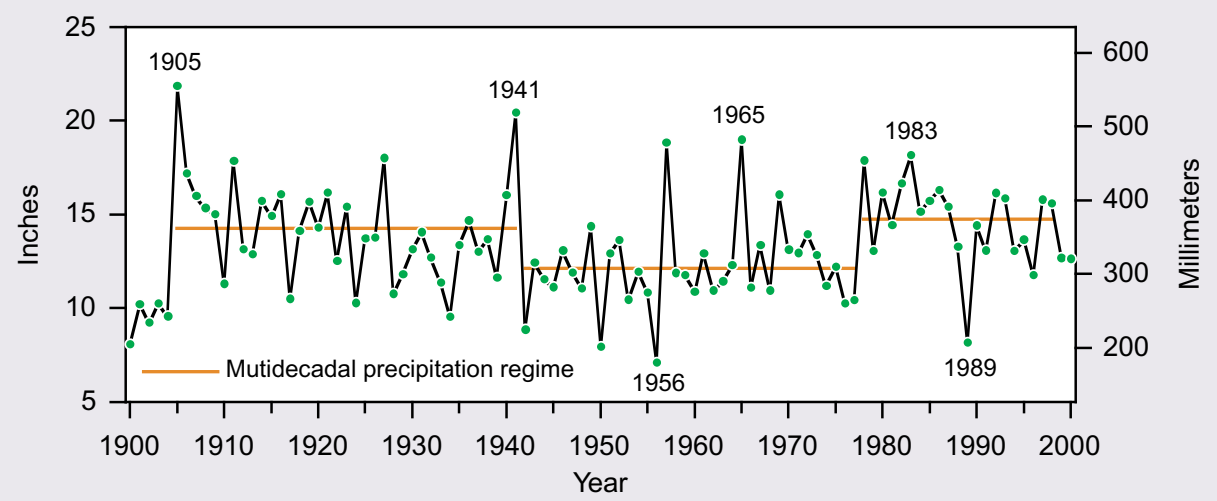

Figure 2. Average annual precipitation recorded at 97 weather stations (see fig. 1) on the Colorado Plateau from 1900 to 2000. Unusually wet and dry years are labeled. Horizontal lines show the average precipitation for three multidecadal precipitation regimes.

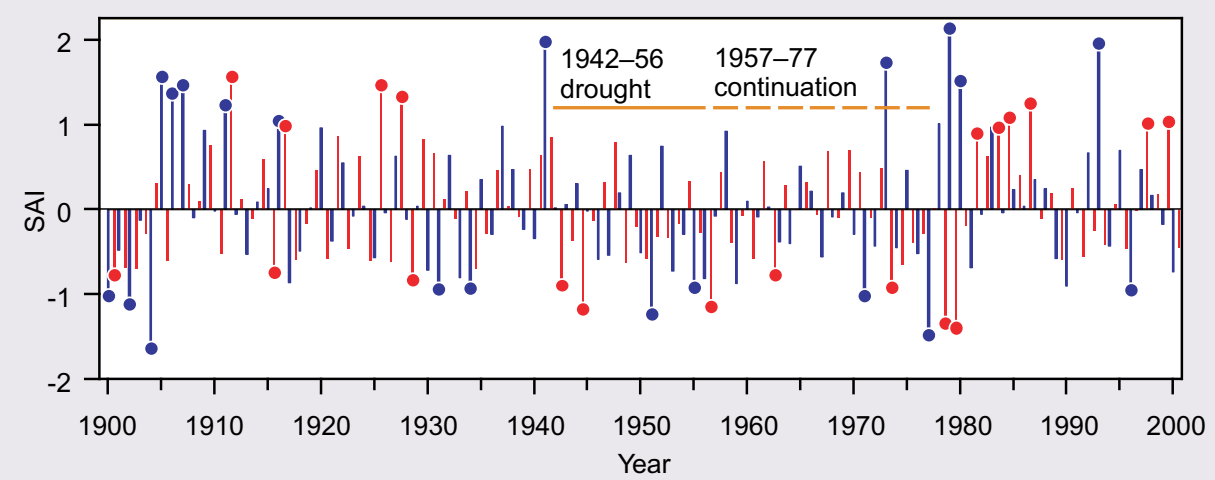

Figure 3. Standardized anomaly index (SAI) of seasonal precipitation for the Colorado Plateau. Blue lines are cool seasons and red lines are warm seasons. Solid circles are the 10 wettest and driest seasons for the period 1900-2000.

11-year drought in the Southwest that began in 1893 (Gatewood, 1962).

The annual variability of precipitation is consistent among the stations. Wet years, defined as having precipitation above the 20th century regional median, typically have more than $50 \%$ of the stations reporting precipitation above the median. From 1942 to 1977 , moisture was below normal at more than $50 \%$ of the stations for 32 of the 36 years. Excluding the 1900-1904 drought and 1999-2000, the relatively wet precipitation regimes (fig. 2) were characterized by wet conditions in 18 of 37 and 14 of 21 years, respectively. Aside from the severe drought of 1989 , climate from 1978 to 1998 was consistently wet compared with the preceding 36 years.

\section{Seasonal Precipitation}

Regional precipitation is biseasonal, occurring mostly during the cool and warm seasons, defined here as October 16 to April 15 and June 15 to October 15, respectively. Cool-season precipitation is caused primarily by frontal systems originating in the eastern North Pacific Ocean. Warm-season rainfall is and atmospheric circulation patterns. These fluctuations operate on two timescales, providing an important means of understanding and predicting precipitation patterns. Shortterm climate variation, with a period of 4 to 7 years, is associated with El Niño and La Niña activity as expressed by several indicators, including the Southern Oscillation Index (SOI) and equatorial SST. Multidecadal climate variation follows a pattern best expressed by the Pacific Decadal Oscillation (PDO), a phenomenon of the northern Pacific Ocean.

\section{Short-Term Variation-El Niño and La Niña}

The SOI is the standardized difference in sea-level atmospheric pressure between Darwin, Australia, and Tahiti. A sustained negative value of the SOI portends the large-scale, anomalous warming of SST in the tropical eastern Pacific Ocean. This phenomenon is generally referred to as El Niño, a term originally applied to the weak, seasonal (usually late December), warm, and south-flowing current off the coast of Peru (Trenberth, 1997). Warm SST in the eastern equatorial Pacific Ocean and sustained negative SOI indicate El Niño conditions, whereas cool SST and sustained positive SOI indicate La Niña conditions. The fully developed interaction between atmosphere and ocean is termed ENSO (El Niño-Southern Oscillation). El Niño conditions tend to bring wet winters to the Southwest and increased streamflow through southerly displacement of storm tracks, although drought may also occur, whereas La Niña conditions reliably bring dry winters (Cayan and others, 1999).

Seasonal precipitation in the Colorado Plateau region correlates negatively with the SOI (fig. 4). The strength of the correlation is modest, but the probability $(P)$ that precipitation is independent of SOI is negligible (that is, probability of no relation is less than 0.05 or $P<0.05)$. Time series of ENSO activity and seasonal precipitation are given in figure 5. Identification of ENSO events and their influence on global and regional climate is the subject of considerable climate research. Indeed, there is no universal definition of what constitutes an ENSO event (Trenberth, 1997). The ENSO chronology plotted in figure 5 is based on the SOI, the SST in the equatorial region of the Pacific Ocean at $5^{\circ} \mathrm{N}$ to $5^{\circ} \mathrm{S}, 90^{\circ}$ to $150^{\circ} \mathrm{W}$ (called the Niño3 region), and the chronologies of Trenberth (1997), Ropelewski (1999), and the Climate Prediction Center (2001). In the following analysis, Colorado 


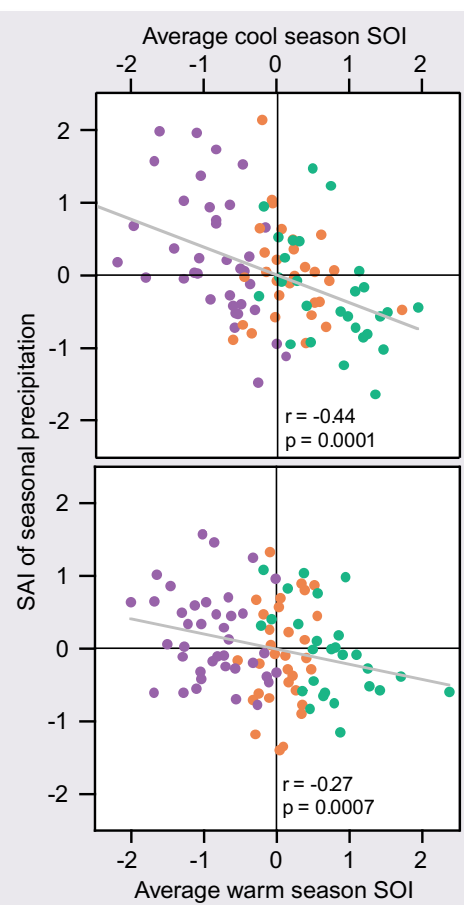

Figure 4. Seasonal precipitation (standardized anomaly index, SAl) for the Colorado Plateau, classified by El Niño-Southern Oscillation (ENSO) or non-ENSO influence as a function of the Southern Oscillation Index (SOI). Purple, light green, and orange symbols are El Niño, La Niña, and non-ENSO, respectively. SOI was averaged over a 7-month window centered on the midpoint of the season.

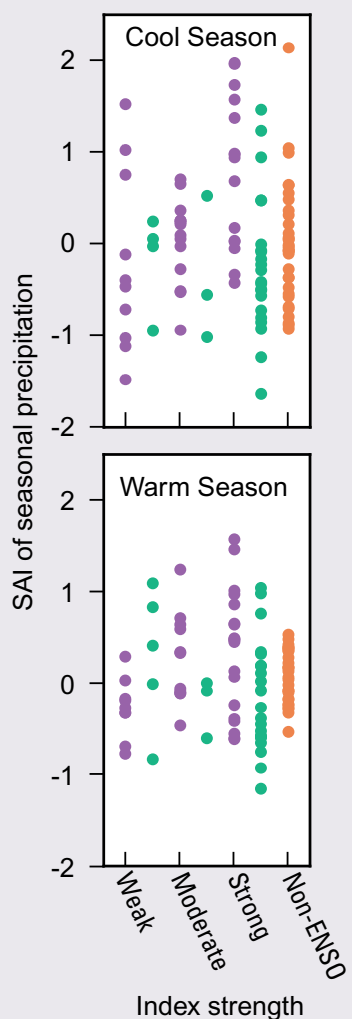

Figure 6. Seasonal precipitation anomalies for the Colorado Plateau classified by strength of EI Niño-Southern Oscillation (ENSO) activity. Color pattern same as figure 4.
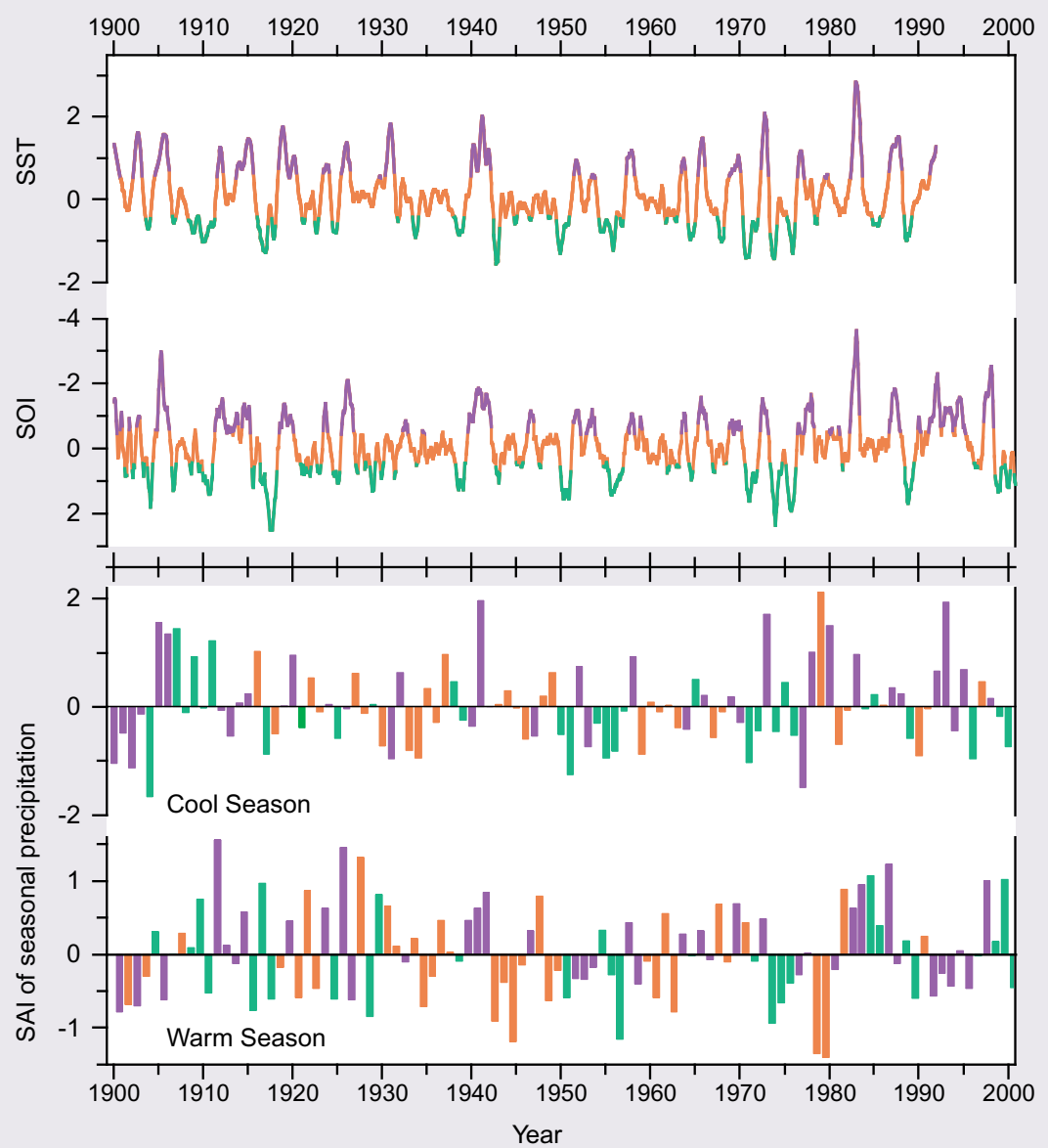

Figure 5. Seasonal precipitation (standardized anomaly index, SAl) for the Colorado Plateau compared with El Niño-Southern Oscillation (ENSO) chronology of sea-surface temperature (SST; Niño3 Indices) and Southern Oscillation Index (SOI). Color pattern same as figure 4. SST and SOI were smoothed with 5-month running average with ENSO threshold conditions for SST of 0.4 and $-0.3^{\circ} \mathrm{C}$ and SOI threshold of \pm 0.5 standard deviation.

Plateau seasonal precipitation was classified as ENSO (El Niño or La Niña ) or non-ENSO (that is, background climate) on the basis of the above sources and the conditions of SST and SOI from the midpoint to 6 months preceding a particular season.

The relation between ENSO and Colorado Plateau precipitation is complicated and contradictory when examined in detail (fig. 5). Nevertheless, several general relations are statistically significant $(P<0.05)$. During El Niño, the frequency of above-normal cool-season precipitation increased above the background climate; on the other hand, precipitation during La Niña is typically less than precipitation during El Niño. ENSO activity varies in strength, which in turn affects precipitation (fig. 6). During both the cool and warm seasons, weak El Niño conditions were usually associated with below-normal precipitation. The variability of warm-season precipitation during strong El Niño events exceeded non-ENSO conditions. Briefly, in both seasons, strong El Niño episodes increased the variability (warm season) of precipitation or the frequency (cool season) of above-normal precipitation relative to non-ENSO climate, whereas strong La Niña episodes typically produced normal, relatively low variability warm-season precipitation and typically below-normal cool-season precipitation.

\section{Long-Term Variation-The PDO}

Recent and possible future climate variation related to the PDO and other ENSO-like indicators of multidecadal climate variability is a recently developed tool for climatological research. The PDO is partly related to SST and atmospheric pressure of the northern Pacific Ocean (Mantua and Hale, 2002). Changes in these parameters evidently trigger sharp transitions from one climate regime to another, altering the climate of North America for periods of 2 to 3 decades (Zhang and others, 1997). Phase shifts of the PDO are thought to affect the spatial connection between ENSO and precipitation in the Western United States (McCabe and Dettinger, 1999). The PDO is not a completely independent predictor of climate variability, because it correlates with and is dependent 


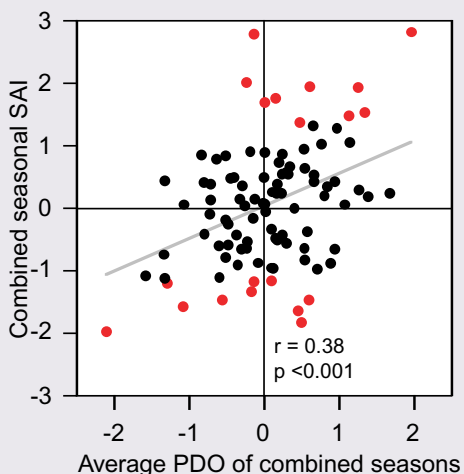

Figure 7. Combined cool and warm season (October 16-October 15) precipitation for the Colorado Plateau as a function of the Pacific Decadal Oscillation (PDO). Ten wettest and driest years shown in red. PDO is averaged over a 14-month window with 7 months preceding and 6 months following the midpoint of the combined season.

on ENSO variability, although it produces essentially the same patterns of temporal variability as more robust indicators.

Precipitation in the Colorado Plateau region is modestly correlated $(P<0.05)$ with the PDO (fig. 7). The three precipitation regimes shown by the annual (fig. 2) and seasonal (fig. 3) precipitation time series are largely in phase with the PDO (fig. 8). This in-phase relation is shown well by the dry episode of 1942-1977, which corresponds to a period of low indices and a prolonged cool phase of the PDO. The early phase of the PDO is associated, although in a complicated manner, with the relatively wet conditions from 1905 to 1941. The strong warm phase of the PDO beginning around 1977 is readily associated with the wet climate beginning in 1978. Of particular interest is the downward shift in the PDO beginning in 1999, with concomitant decreased precipitation that continued through the winter of 2002. The weather, SST, and surface-pressure patterns of 1999-2002 suggest to climatologists that the transition to another regime is presently underway (Ze'ev and Smith, 2001), signaling the end of the warm PDO phase and the wet climate of 1978-1998.

\section{Implications}

Precipitation in the Colorado Plateau region has varied substantially during the past century. This multidecadal variability has implications for ecosystem processes and land management. Precipitation, along with other climate variables, affects the spatial scale, frequency, and magnitude of natural disturbances to the ecosystem (Swetnam and Betancourt, 1998) as well as the recovery rates from natural and human disturbances. For example, the results of

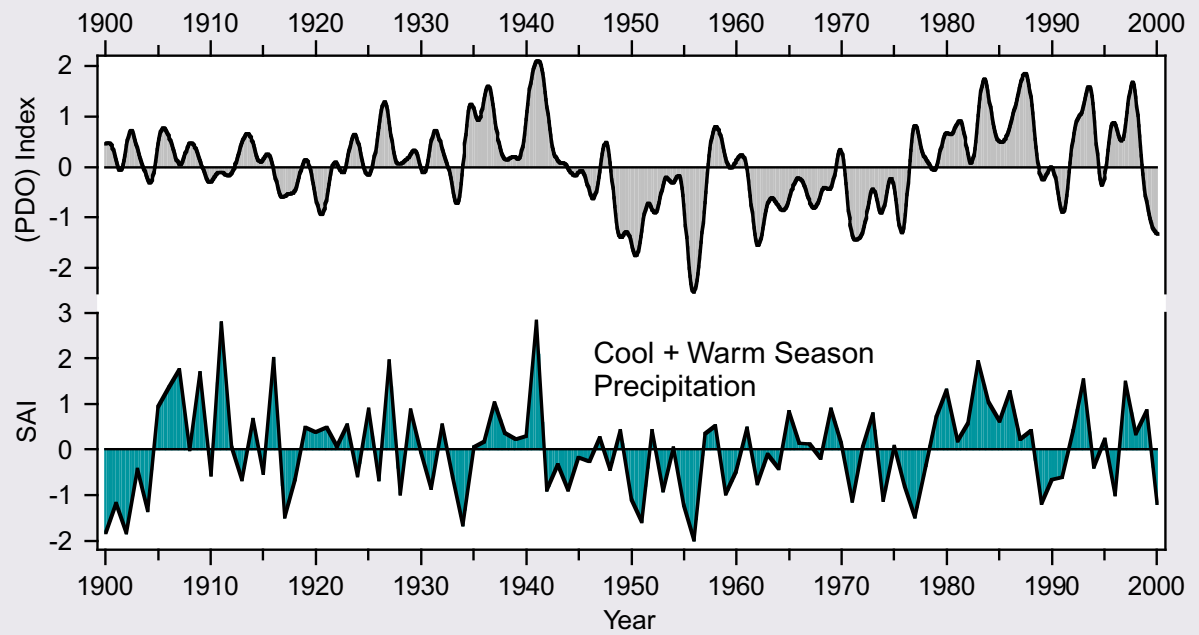

Figure 8. Smoothed (15-month moving window using the Savitzsky-Golay procedure) monthly indices of the Pacific Decadal Oscillation (PDO) (upper) and combined seasonal precipitation (standardized anomaly index, SAI) (lower) for the Colorado Plateau.

studies of floral and faunal population dynamics and the affects of grazing are dependent on the prevailing climate. Inferences and projections based on these studies may not be valid or may need adjustment or reappraisal if applied during a different climate regime.

Recent trends in Colorado Plateau precipitation and the PDO suggest that the climate of the region may become drier for the next 2 to 3 decades in a pattern that could resemble the drought of 1942-1977. Although there are many uncertainties and assumptions, including using a single index (PDO) to predict multidecadal climate variability (Schmidt and Webb, 2001), it is important to consider the potential affects of climate variation on the human and natural resources of the region. Water resources were heavily affected during the early part of the 1942-1977 drought (Gatewood and others, 1964). The population of the region has increased fourfold since the mid-1950s, substantially increasing the demand for water in a region without abundant supplies and creating the possibility of severe or catastrophic consequences if such a drought were repeated.

The work of USGS and other scientists is leading to a better understanding of the past and probable future climate of the Colorado Plateau. This work is only part of USGS efforts to provide information crucial to sound planning policies for land use and energy and other resource management. These efforts are also helping to protect lives and property from drought, landslides, and other hazards.

\section{Richard Hereford, Robert H. Webb, and Scott Graham}

Edited by James W. Hendley II and Peter H. Stauffer Graphic design by Sara Boore and Susan Mayfield

\section{References}

Cayan, D.R., Redmond, K.T., and Riddle, L.G., 1999, ENSO and hydrologic extremes in the western United States: Journal of Climate, v. 12, p. 2881-2893.

Gatewood, J.S., 1962, The meteorologic phenomenon of drought in the Southwest: U.S. Geological Survey Professional Paper 372-A, p. A1-A43.

Gatewood, J.S., Wilson, A., Thomas, H.E., and Kister, L.R., 1964, General effects of drought on water resources of the Southwest, 1942-1956: U.S. Geological Survey Professional Paper 372-B, p. B1-B55.

Mantua, N.J., and Hare, S.R., 2002, The Pacific decadal oscillation: Journal of Oceanography, v. 58, p. 35-42.

McCabe, J.G., and Dettinger, M.D., 1999, Decadal variations in the strength of ENSO teleconnections with precipitation in the western United States: International Journal of Climatology, v. 19 , p. 1399-1410.

Ropelewski, C., 1999, The great El Niño of 1997-1998-Impacts on precipitation and temperature: Consequences, v. 5, p. 17-25.

Schmidt, K.M., and Webb, R.H., 2001, Researchers consider U.S Southwest's response to warmer, drier conditions: Eos, Transactions, American Geophysical Union, v. 82, p. 475, 478.

Swetnam, T.W., and Betancourt, J.L., 1998, Mesoscale disturbance and ecological response to decadal climate variability in the American Southwest: Journal of Climate, v. 11, p. 3128-3147.

Trenberth, K.E., 1997, The definition of El Niño: Bulletin of the American Meteorological Society, v. 78, p. 2271-2777.

Ze'ev, G., and Smith, D.J., 2001, Interdecadal climate variability and regime-scale shifts in Pacific North America: Geophysical Research Letters, v. 28, p. 1515-1518.

Zhang, Y., Wallace, J.M., and Battisti, D.S., 1997, ENSO-like interdecadal variability -1900-93: Journal of Climate: v. 10, p 1004-1020.

\section{Websites}

Climate Prediction Center, Previous ENSO events (1877-present): http://www.cpc.ncep.noaa.gov/.../ensoyears_1877present.htm; accessed August 31, 2001.

Niño3 Indices, http://ingrid.Ideo.columbia.edu/SOURCES/ .KAPLAN/.Indices/.NINO3/.avGOSTA/; accessed June 20, 2001.

Pacific Decadal Oscillation data: N. Mantua http:// tao.atmos.washington.edu/pdo; accessed June 19, 2000

SOI Indices, http://www.cpc.ncep.noaa.gov/data/indices/ index.html; accessed July 9, 2001

$$
\begin{gathered}
\text { For more information contact } \\
\text { Scientist-in-Charge } \\
\text { U.S. Geological Survey } \\
2255 \text { North Gemini Drive } \\
\text { Flagstaff, AZ } 86001 \\
\text { (928) } 556-7024 \\
\text { or }
\end{gathered}
$$

http://climchange.cr.usgs.gov/info/sw/

This fact sheet and any updates to it are available online at: http://geopubs.wr.usgs.gov/fact-sheet/fs119-02/ 